\title{
Determination of the standard Gibbs energies of transfer of cations across the nitrobenzene|water interface utilizing the reduction of iodine in an immobilized nitrobenzene droplet
}

\author{
Valentin Mirčeski ${ }^{1}$, Rubin Gulaboski, Fritz Scholz * \\ Ernst-Moritz-Arndt-Universität Greifswald, Institut für Chemie und Biochemie, Soldmannstraße 23, D-17489 Greifswald, Germany
}

Received 16 August 2002; accepted 27 August 2002

\begin{abstract}
When a nitrobenzene (NB) droplet containing iodine is attached to a graphite electrode and immersed into a chloride containing aqueous (AQ) solution, the electrochemical reduction of iodine is accompanied by a transfer of chloride ions from NB to water. These chloride ions enter the NB phase in a preceding partition between the AQ and the NB phases, supported by formation of $\mathrm{I}_{2} \mathrm{Cl}^{-}$ions in $\mathrm{NB}$ and accompanied by the transfer of stoichiometric amounts of cations. The overall electrode reaction is of $\mathrm{CE}_{\text {rev }}$ type, where $\mathrm{C}$ refers to the preceding chemical step forming $\mathrm{I}_{2} \mathrm{Cl}^{-}$, and $E_{\mathrm{rev}}$ refers to the reversible reduction of iodine at the graphite|NB interface and the simultaneous transfer of chloride from NB to water. If the chloride concentration in NB is insufficient to compensate by leaving the NB the amount of electrochemically produced iodide, a second voltammetric signal occurs at more negative potentials due to the transfer of iodide from NB to water. The kinetics and thermodynamics of the preceding chemical step $\mathrm{C}$, determine the voltammetric behaviour of the system in such way that the ratio of peak currents of the first and second signals depends linearly on the Gibbs energy of transfer of the co-partitioned cations. The method was validated for cations of known Gibbs energies of transfer, and it was applied to cations of amino acids.
\end{abstract}

(c) 2002 Published by Elsevier Science B.V.

Keywords: Voltammetry; Iodine; Three-phase junction; Cation transfer

\section{Introduction}

Electrochemical reactions occurring at geometrically well-defined three-phase junctions [1-6] attract considerable attention, since they allow detailed studies of coupled electron and ion transfer processes. The electrochemical oxidation of a neutral compound (e.g. decamethylferrocene) dissolved in the organic phase of a three-phase system electrode|organic liquid|AQ solution, allows us to study the ion transfer across the liquid|liquid interface, and it provides access to the Gibbs energies of ion transfer [7-10]. Ion transfer at liquid|liquid interfaces

\footnotetext{
${ }^{*}$ Corresponding author. Tel.: +49-0-3834-86-4450; fax: +49-0-383486-4451.

E-mail address: fscholz@uni-greifswald.de (F. Scholz).

${ }^{1}$ On leave from: Institute of Chemistry, Faculty of Natural Sciences, and Mathematics, "Sv. Kiril i Metodij" University, P.O. Box 162, 1000 Skopje, Republic of Macedonia.
}

is of fundamental importance for drug uptake [11], phase transfer catalysis [12], ion-selective electrodes [13], biomimetic studies of membrane function, etc. [14].

Shi and Anson [15] used uniform thin films on an electrode surface to study the coupled electron and ion transfer in three-phase arrangements with a three-electrode potentiostat. The film remains insulating when there is not a sufficient partition of the salt present in the AQ phase. Another constrain is that the initial partition of the salt determines the concentration of ions in the film which in turn determines the formal potential of the redox probe in the film. An attached droplet can be regarded as a film with a thickness varying from zero to rather large values. The fact that the droplet has zero thickness at its circumference, i.e. at the three-phase junction line, allows the electron transfer reaction to start with any kind of ions in the AQ phase. After the start, it reaches thicker layers of the droplet where the initial partition is without negligible. Gibbs energy of 
ion transfer can be calculated on the basis of a Nernst equation (see [7]) knowing only the concentration of the transferable ions in the AQ phase and the concentration of the redox probe in the organic phase.

Recently, we reported on the electrochemical reduction of iodine at the three-phase arrangement graphite electrode $|\mathrm{NB}| \mathrm{AQ}$ electrolyte [10]. The three-phase set-up consists of a droplet of NB containing the dissolved neutral electroactive compound (here iodine), which is attached to the surface of a graphite electrode and immersed in the AQ electrolyte solution. The electrode mechanism depends considerably on the chemical composition of the AQ phase [10]. The introduction of the electrode with the immobilised NB droplet into the AQ phase prompts an fast partition of the salt that was dissolved in the AQ phase between the latter and a surface layer of the droplet. In the presence of a chloride salt in the AQ phase, the reaction of iodine in the organic phase is accompanied by the expulsion of partitioned chloride ions from NB to water, instead of being accompanied by the transfer of cations from water to NB. The important result of the present study is that the peak currents of iodine reduction connected with chloride expulsion linearly depend on the standard Gibbs energies of transfer of the cations across the water|NB interface. With the help of this system, a novel voltammetric method for estimation of the standard Gibbs energy of cation transfer is proposed and it was applied to determine these data of the cations of the amino acids phenylalanine (Phe) and alanine (Ala). The estimated data are in good agreement with reported values [16].

\section{Experimental}

If not specified otherwise, a $0.1 \mathrm{~mol} \mathrm{dm}^{-3}$ iodine solution in water saturated NB was prepared. $2 \mu \mathrm{L}$ of this solution were attached as a droplet to the surface of paraffin impregnated graphite electrode (PIGE [2]) by help of an Eppendorf-type pipette. The radius of the attached hemispherical droplet was about $0.1 \mathrm{~cm}$ and the length of the three-phase boundary surrounding the droplet was $0.62 \mathrm{~cm}$. The electrode was immersed in the AQ electrolyte solution and voltammograms were recorded using a three-electrode electrochemical cell.

After preliminary studies with cyclic voltammetry, square-wave (SW) voltammetry was used in all following measurements because of the superior precision of peak potential measurements. SW voltammograms were recorded using a $\mu$ AUTOLAB (Eco-Chemie, Utrecht, Netherlands). A Ag $|\mathrm{AgCl}| \mathrm{NaCl}$ (sat.) solution reference electrode ( $E=0.200 \mathrm{~V}$ vs. SHE) was used and a platinum wire served as auxiliary electrode.

All chemicals used were of analytical grade and used as purchased. Double distilled water was used. All experiments were carried out at room temperature. The amino acids phenylalanine and alanine were products of Sigma-Aldrich.

\section{Results and discussion}

\subsection{Iodine reduction coupled to iodide expulsion from $N B$}

In the three-phase arrangement, electrode|NB droplet|water $(\mathrm{E}|\mathrm{NB}| \mathrm{W})$, iodine can be reversibly reduced to iodide, yielding a well-defined SW voltammetric response [10]. The electrode reaction is accompanied by an ion transfer across the $\mathrm{NB} \mid \mathrm{W}$ interface to maintain the electroneutrality of the organic phase. When the AQ phase contains $\mathrm{NO}_{3}^{-}, \mathrm{SO}_{4}^{2-}$ or $\mathrm{F}^{-}$and $\mathrm{Cs}^{+}, \mathrm{Na}^{+}, \mathrm{K}^{+}, \mathrm{NH}_{4}^{+}$or $\mathrm{Mg}^{2+}$, the reduction of iodine in the three-phase arrangement is accompanied by an expulsion from NB of electrochemically generated iodide ions. Therefore, a single SW peak is observed at $0.47 \mathrm{~V}$, due to the reactions

Reaction Scheme (I)

$\mathrm{I}_{2(\mathrm{NB})}+2 \mathrm{e}^{-} \rightleftarrows 2 \mathrm{I}_{(\mathrm{NB})}^{-}$

$2 \mathrm{I}_{(\mathrm{NB})}^{-} \rightleftarrows 2 \mathrm{I}_{(\mathrm{W})}^{-}$

\subsection{Iodine reduction coupled to chloride expulsion from} $N B$

When chloride ions are present in the AQ phase, a new SW peak appears at more positive potentials. Fig. 1 shows the net, forward (reduction), and backward (oxidation) components of the SW voltammetric response of iodine in the presence of $\mathrm{Cl}^{-}$in the AQ phase. The

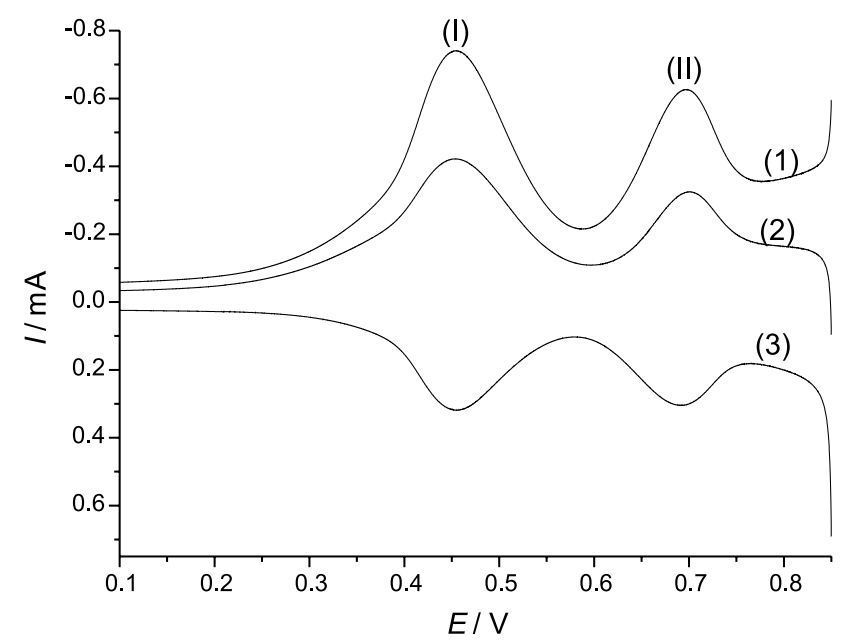

Fig. 1. The net (1), forward (2), and backward (3) component of the square-wave voltammetric response of a NB droplet containing 0.1 mol dm ${ }^{-3}$ iodine attached to a paraffin impregnated graphite electrode and immersed in $0.25 \mathrm{~mol} \mathrm{dm}^{-3} \mathrm{NaCl}$ AQ solution. The experimental conditions were: SW frequency $f=50 \mathrm{~Hz}, \mathrm{SW}$ amplitude $E_{\mathrm{sw}}=50 \mathrm{mV}$, scan increment $\mathrm{d} E=0.15 \mathrm{mV}$, and start potential $E_{\mathrm{s}}=0.90 \mathrm{~V}$. 
position of the second SW peak shifts $-60 \mathrm{mV}$ per decade of $\mathrm{Cl}^{-}$concentration increase in water, implying that the reduction of iodine is followed by a transfer of chloride from NB into the AQ solution (reaction Scheme II) (see ref. [10]).

Reaction Scheme(II)

$\mathrm{I}_{2(\mathrm{NB})}+2 \mathrm{e}^{-} \rightleftarrows 2 \mathrm{I}_{(\mathrm{NB})}^{-}$

$2 \mathrm{Cl}_{(\mathrm{NB})}^{-} \rightleftarrows 2 \mathrm{Cl}_{(\mathrm{W})}^{-}$

This finding was unexpected for the following reasons:

(i) No supporting electrolyte was added to the NB.

(ii) The experiment was not performed with a thin film, as in Ansons experiments [15], where a quick partition between the AQ phase and the entire organic phase takes place.

(iii) Even if quick partition is assumed, the equilibrium concentration of $\mathrm{NaCl}$ in $\mathrm{NB}$ would be $6.03 \times 10^{-8} \mathrm{~mol} \mathrm{dm}^{-3}$ if the concentration in water is $0.1 \mathrm{~mol} \mathrm{dm}^{-3} \mathrm{NaCl}$ [17].

Such low concentration would not suffice to maintain a current as shown in Fig. 1 (peak II). The height of the response of reaction Scheme II should be negligible compared to that of reaction Scheme I, which is determined solely by the concentration of iodine $(0.1 \mathrm{~mol}$ $\mathrm{dm}^{-3}$ ). An additional preceding chemical process must provide a considerably higher concentration of chloride inside the NB. It is reasonable to assume the formation of interhalide compounds of the type $\mathrm{I}_{2} \mathrm{X}^{-}$, where $\mathrm{X}^{-}$ can be $\mathrm{Cl}^{-}$or $\mathrm{Br}^{-}$[18]. The stability of such complexes in an AQ medium is rather low. However, they might be stabilised in NB in which iodine is highly soluble and which is characterised by a lower permittivity than water. The formation of $\mathrm{I}_{2} \mathrm{Cl}^{-}$was confirmed by studying the reduction of $\mathrm{I}_{2}$ in $\mathrm{NB}$, containing $0.1 \mathrm{~mol} \mathrm{dm}^{-3}$ tetrabuthylamonium hexafluorophosphate, $5 \times 10^{-4}$ mol dm${ }^{-3}$ iodine and $\mathrm{CsCl}$ (from $1 \times 10^{-3}$ up to $5 \times$ $10^{-3} \mathrm{~mol} \mathrm{dm}^{-3}$ ), using a $\mathrm{Pt}$ electrode. If the reaction $\mathrm{I}_{2(\mathrm{NB})}+\mathrm{Cl}_{(\mathrm{NB})}^{-} \leftrightarrows \mathrm{I}_{2} \mathrm{Cl}_{(\mathrm{NB})}^{-}$occurs, the formal potential of the reduction of iodine to iodide should shift $28.5 \mathrm{mV}$ per decade of increase of $\mathrm{Cl}^{-}$concentration. The experiment gives a linear relationship of the formal potential versus $\log \left(c_{\mathrm{Cl}^{-}}\right)\left(R^{2}=0.9902\right)$ and a slope of $-24 \mathrm{mV}$.

Increasing the time of equilibration between the two liquid phases prior to the applied potential scan further supports the idea of a preceding process: an increase of the equilibration time from 0 to $200 \mathrm{~s}$, caused a proportional increase of the peak current ratio $I_{\mathrm{p}}(\mathrm{II}) / I_{\mathrm{p}}(\mathrm{I})$ from 0.28 to 0.6 , when $0.25 \mathrm{~mol} \mathrm{dm}^{-3} \mathrm{NaCl}$ solution was used as aqueous phase. $I_{\mathrm{p}}(\mathrm{II}) / I_{\mathrm{p}}(\mathrm{I})$ increases only because peak (II) increases, since the height of the peak (I) is determined by the concentration of iodine in NB, which was kept constant. For longer equilibration times, the peak current ratio remained virtually constant. The results indicate a rather slow equilibration, probably because the two phases are quiet (not stirred). Since a precise control of the size of the immobilised droplet is rather difficult, the ratio of peak currents $I_{\mathrm{p}}(\mathrm{II}) / I_{\mathrm{p}}(\mathrm{I})$ was chosen for all quantitative evaluations. It was proven in independent experiments that $I_{\mathrm{p}}$ (II) behaves as deduced from the ratio determinations, and $I_{\mathrm{p}}(\mathrm{I})$ is constant. Additional support for the presence of a chemical reaction preceding the electrode reduction of iodine was provided by analysing the peak current ratio as a function of the SW frequency $f$. By increasing the frequency from 10 to $250 \mathrm{~Hz}$, the ratio $I_{\mathrm{p}}(\mathrm{II}) / I_{\mathrm{p}}(\mathrm{I})$ decreases exponentially from 0.68 to 0.08 . In the previous study [10] it has been proved that reaction (1) is a diffusion controlled process, and hence $I_{\mathrm{p}}(\mathrm{I})$ increases proportionally to the square root of the SW frequency. The decrease of the peak ratio $I_{\mathrm{p}}(\mathrm{II}) / I_{\mathrm{p}}(\mathrm{I})$ by decreasing the time window of the voltammetric experiments, is mainly due to the diminishing of the peak (II). The decrease of the peak current by increasing the signal frequency is a characteristic property of a CE mechanism [19]. A good linear dependence $\left(R^{2}=0.972\right)$ of the peak current ratio on the logarithm of the inverse signal frequency was observed (data not shown), just as described for a $\mathrm{CE}$ mechanism [19], where $C$ is a chemical reaction preceding the electrochemical step E:

$$
\begin{array}{ll}
\mathrm{C}: & \mathrm{Y} \underset{k_{-1}}{\stackrel{k_{1}}{\rightleftarrows}} \mathrm{Ox} \\
\mathrm{E}: & \mathrm{Ox}+n \mathrm{e}^{-} \rightleftarrows \mathrm{Red}
\end{array}
$$

For the iodine system follows:

Reaction Scheme III (cf. Fig. 5)

$$
\begin{array}{ll}
\mathrm{C}: & \mathrm{I}_{2(\mathrm{NB})}+\mathrm{Cl}_{(\mathrm{W})}^{-}+\mathrm{Cat}_{(\mathrm{W})}^{+} \rightleftarrows \mathrm{I}_{2} \mathrm{Cl}_{(\mathrm{NB})}^{-}+\mathrm{Cat}_{(\mathrm{NB})}^{+} \\
\mathrm{E}: & \mathrm{I}_{2(\mathrm{NB})}+2 \mathrm{e}^{-} \rightleftarrows 2 \mathrm{I}_{(\mathrm{NB})}^{-} \\
& 2 \mathrm{Cl}_{(\mathrm{NB})}^{-} \rightleftarrows 2 \mathrm{Cl}_{(\mathrm{W})}^{-}
\end{array}
$$

There is certainly also the possibility that $\mathrm{I}_{2} \mathrm{Cl}_{(\mathrm{NB})}^{-}$is reduced instead of $I_{2(N B)}$. Reaction $C$ is a reactive partition, i.e. a partition facilitated by a chemical reaction, i.e. here the formation of $\mathrm{I}_{2} \mathrm{Cl}_{(\mathrm{NB})}^{-}$accompanied by a cotransfer of cations to maintain charge neutrality. Both reactions written for $\mathrm{E}$ proceed simultaneously and both are electrochemical processes. The chloride ions to be expelled from NB are present due to the equilibrium $\mathrm{I}_{2(\mathrm{NB})}+\mathrm{Cl}_{(\mathrm{NB})}^{-} \rightleftarrows \mathrm{I}_{2} \mathrm{Cl}_{(\mathrm{NB})}^{-}$. The reaction scheme III involves in both the chemical and the electrochemical parts a phase transfer of ions. Thus it is much more complicate than the simple CE mechanism reported in literature [19]. However, a detailed kinetic analysis involving all reaction and transport steps is not possible at this stage of the work. The voltammetric behaviour of a 
CE mechanism is determined by the kinetic parameter $\varepsilon=\left(k_{1}+k_{-1}\right) / f$ and the equilibrium constant $K=$ $k_{1} / k_{-1}$. Here $k_{1}$ and $k_{-1}$ are pseudo-first order chemical rate constants of the forward and backward chemical reaction, respectively, and $f$ is the SW frequency. For a CE mechanism O'Dea et al. [19] have shown that, within the ranges $-3 \leqslant \log (\varepsilon) \leqslant 3$, and $-3 \leqslant \log (K) \leqslant 3$, the peak currents depend sigmoidally on the logarithm of $K$ and $\varepsilon$ (see Fig. 10 [19]). Within narrower intervals, the dependencies can be approximated by a linear function. For instance the theoretical relationships of the SW peak current on the logarithm $\varepsilon$ (for $K=1$ ) and logarithm $K$ (for $\varepsilon=2)$ are exactly linear with a correlation coefficient of $R^{2}=0.99$ in both cases.

The experiments show that the iodine reduction in the present system are in complete agreement with the theory [19]. Thus, the linear dependence of $I_{\mathrm{p}}(\mathrm{II}) / I_{\mathrm{p}}(\mathrm{I})$ on $\log \left(f^{-1}\right)$ ( $f$ is the $\mathrm{SW}$ frequency) is in accordance with assuming a $\mathrm{CE}$ mechanism, since it corresponds to the theoretical dependence on the kinetic parameter $\varepsilon$ (see Fig. 10 in [19]).

Variation of the $\mathrm{Cl}^{-}$concentration in the AQ phase provided further evidences for a $\mathrm{CE}$ mechanism. The peak current ratio increases linearly with the logarithm of the chloride concentration in the AQ phase (Fig. 2), indicating that chloride ions are involved in the preceding chemical step. The relationship $I_{\mathrm{p}}(\mathrm{II}) / I_{\mathrm{p}}(\mathrm{I})$ versus $\log \left(c_{\left.\mathrm{Cl}_{(\mathrm{W})}^{-}\right)}\right)$also corresponds to the theoretical dependence of the peak current on the kinetic parameter $\varepsilon$, since the

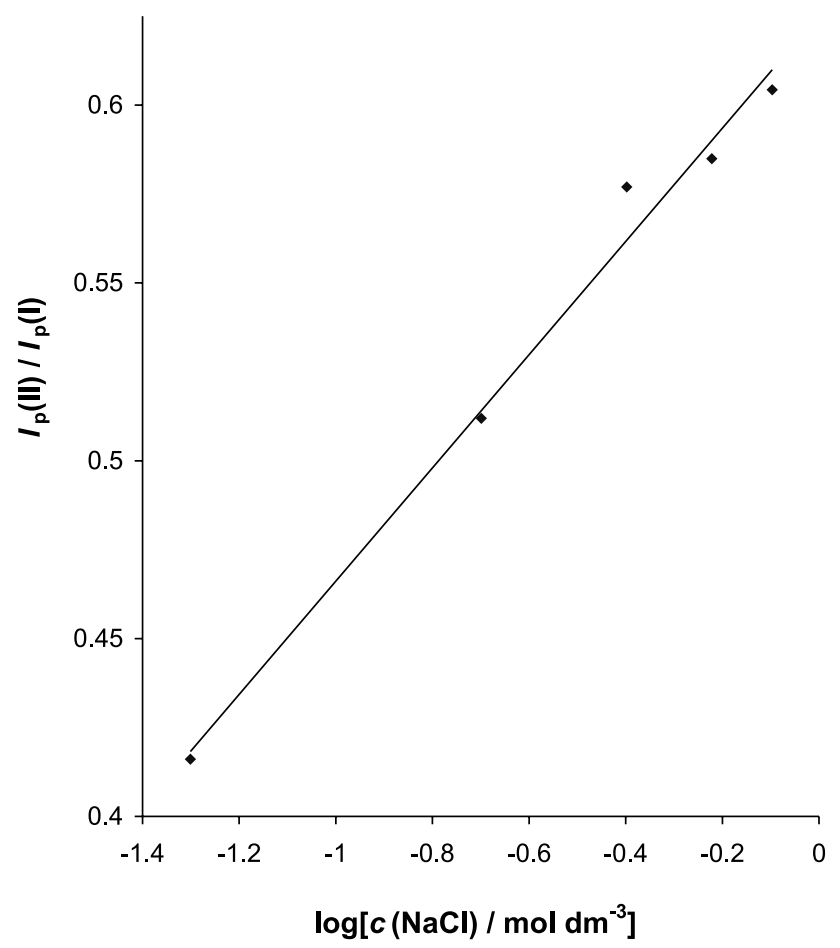

Fig. 2. The dependence of the peak current ratio $I_{\mathrm{p}}(\mathrm{II}) / I_{\mathrm{p}}(\mathrm{I})$ on the logarithm of $\mathrm{Cl}^{-}$concentration, measured by increasing the concentration of $\mathrm{NaCl}$ in the $\mathrm{AQ}$ phase. Other experimental conditions were the same as in Fig. 1.

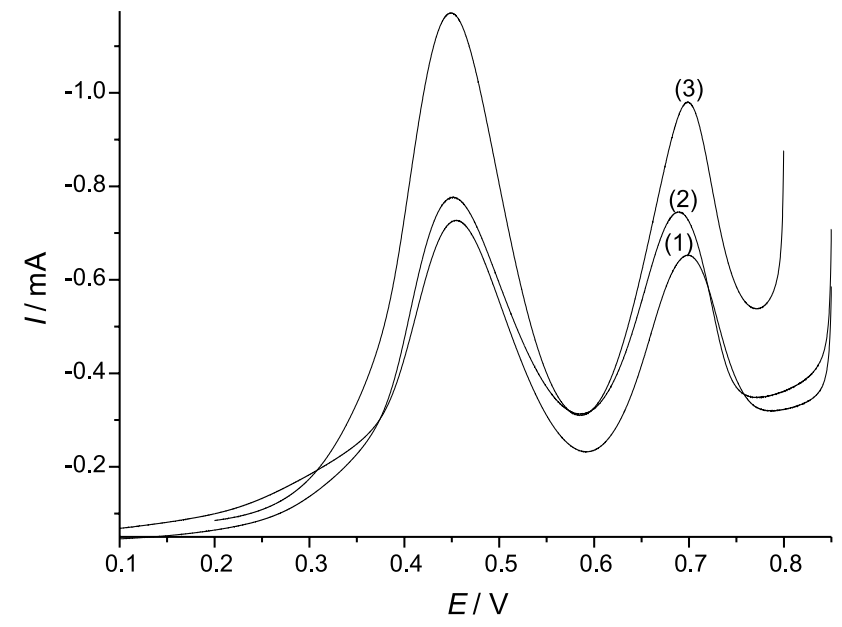

Fig. 3. Net SW responses of NB droplet containing $0.1 \mathrm{~mol} \mathrm{dm}^{-3}$ iodine attached to a paraffin impregnated graphite electrode, which was immersed in the AQ phase containing $0.25 \mathrm{~mol} \mathrm{dm}^{-3}$ solution of $\mathrm{NaCl}$ (curve 1), $\mathrm{KCl}$ (curve 2), and $\mathrm{HCl}$ (curve 3). Other experimental conditions were the same as in Fig. 1.

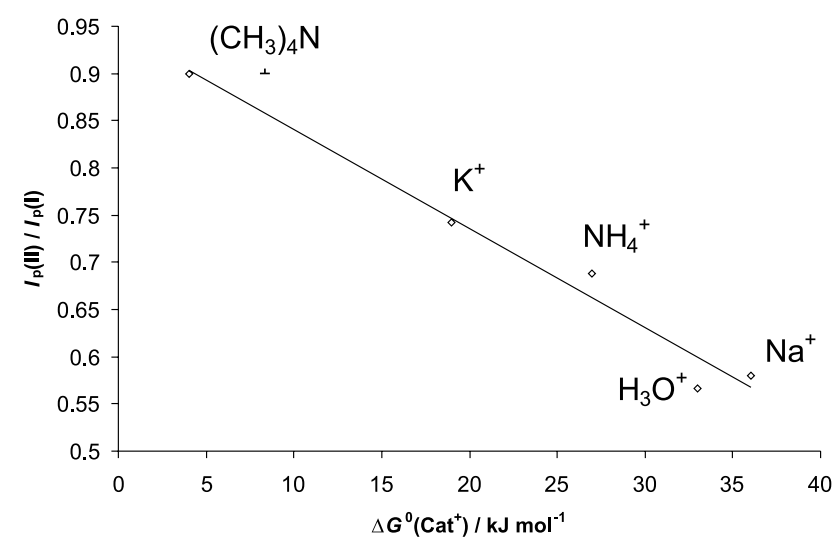

Fig. 4. The correlation of the peak current ratio with the standard Gibbs energy of cation-transfer from water into NB for different cations present in the chloride AQ phase $\left(R^{2}=0.9742\right)$. Other conditions were the same as in Fig. 3.

variation of the concentration of chloride ions is equivalent to a variation of the pseudo first order rate constant $k_{1}$ of scheme (III).

The peak current ratio is sensitive to the iodine concentration, suggesting that iodine is a reactant in the preceding chemical reaction. It is also important to note that the electrochemically formed iodide can react further with iodine to form the stable $\mathrm{I}_{3}^{-}$complex in the organic phase

$\mathrm{I}_{(\mathrm{NB})}^{-}+\mathrm{I}_{2(\mathrm{NB})} \rightleftarrows \mathrm{I}_{3(\mathrm{NB})}^{-}$

The Nernst equation for the iodine reduction and $\mathrm{I}_{3}^{-}$ formation follows as

$E=E_{\mathrm{I}_{2} \mid \mathrm{I}^{-}(\mathrm{NB})}^{\theta}+\frac{R T}{F} \ln K+\frac{R T}{F} \ln a_{\mathrm{I}_{2}(\mathrm{NB})}+\frac{R T}{2 F} \ln \frac{a_{\mathrm{I}_{2}(\mathrm{NB})}}{a_{\mathrm{I}_{3}^{-}(\mathrm{NB})}}$, 
where $K$ is the equilibrium constant of the reaction (4). The relationship $E_{\mathrm{p}(\mathrm{II})}$ versus $\log \left(c_{\mathrm{I}_{2}(\mathrm{NB})}\right)$ is linear with a positive slope of $62 \mathrm{mV}$, which is in agreement with the latter Nernst equation.

In a rigorous treatment, the formation of $\mathrm{I}_{2} \mathrm{Cl}^{-}$in the AQ phase should be also taken into account, and hence its partition, however, due to the low solubility of iodine in water and the small stability constant of these ions in water, that side was neglected here.

\subsection{The role of cations when iodine reduction is coupled by chloride expulsion from $N B$}

In order to study the influence of increasing cation concentration, experiments have been performed with $0.25 \mathrm{~mol} \mathrm{dm}^{-3} \mathrm{NaCl}$ solutions, to which certain amounts of $\mathrm{NaNO}_{3}$ were subsequently added i.e. chloride concentration was kept constant, whereas the $\mathrm{Na}^{+}$ concentration was increased from 0.2 to $1 \mathrm{~mol} \mathrm{dm}^{-3}$. $\mathrm{NO}_{3}^{-}$ions exhibit no influence on mechanisms (I) and (II). The peak current ratio was not affected by increasing the $\mathrm{Na}^{+}$concentration. This shows that the cotransfer of cations in reaction (1) (scheme III) is not rate determining and does not contribute to the overall kinetics of this reaction. The transfer of ions across liquid|liquid interfaces is known to be very fast [20].

Further experiments were performed in the presence of $0.25 \mathrm{~mol} \mathrm{dm}{ }^{-3} \mathrm{Cat}^{+} \mathrm{Cl}^{-}$solutions, where $\mathrm{Cat}^{+}$was $\mathrm{Na}^{+}, \mathrm{H}^{+}, \mathrm{NH}_{4}^{+}, \mathrm{K}^{+}$, and $\mathrm{TMA}^{+}$. Fig. 3 shows $\mathrm{SW}$ voltammograms recorded in three different aqueous solutions containing $0.25 \mathrm{~mol} \mathrm{dm}{ }^{-3} \mathrm{HCl}, \mathrm{KCl}$, and $\mathrm{NaCl}$. The peak current ratio depends on the cation type present in the aqueous phase. Moreover, a good correlation between the peak current ratio and the standard Gibbs energy of transfer of the cations was observed (see Fig. 4).

Although the transfer of the cations does not influence the kinetics of the preceding chemical reaction, it affects the thermodynamics of the reaction (1). The equilibrium constant $K$ of reaction (1) is defined as
$K=\exp \left(-\Delta G^{\theta} / R T\right)$, where $\Delta G^{\theta}$ is the standard Gibbs energy of reaction (1), while $R$ and $T$ have their usual meaning. $\Delta G^{\theta}$ of reaction (1) is the sum of the standard Gibbs energies of the chemical reaction $\mathrm{I}_{2(\mathrm{NB})}+$ $\mathrm{Cl}_{(\mathrm{W})}^{-} \rightleftarrows \mathrm{I}_{2} \mathrm{Cl}_{(\mathrm{NB})}^{-}$and the standard Gibbs energy of cation transfer reaction $\mathrm{Cat}_{(\mathrm{W})}^{+} \rightleftarrows \mathrm{Cat}_{(\mathrm{NB})}^{+}$, i.e. $\Delta G^{\theta}=$ $\Delta G_{\mathrm{I}_{2} \mathrm{Cl}^{-}}+\Delta_{\mathrm{W}}^{\mathrm{NB}} G_{\mathrm{Cat}^{+}}^{\theta}$. Variation of the cations in the aqueous phase, the standard Gibbs energy of reaction (1) is affected by $\Delta_{\mathrm{W}}^{\mathrm{NB}} G_{\mathrm{Cat}^{+}}^{\theta}$, i.e. the standard Gibbs energy of the cation transfer across the $\mathrm{W} \mid \mathrm{NB}$ interface.

The linear relationship between the standard Gibbs energy of cation transfer is in agreement with the expected properties of the CE electrode mechanism. As mentioned previously, for a constant kinetic parameter of the preceding chemical reaction, the peak current is a linear function of the logarithm of the equilibrium constant. The logarithmic dependence on the equilibrium constant is equivalent to the linear dependence on the standard Gibbs energy of the chemical reaction. For these reasons, the peak current ratio of the voltammetric responses of iodine reduction in the three-phase arrangement can be correlated with the standard Gibbs energy of transfer of cations across the $\mathrm{W} \mid \mathrm{NB}$ interface. This feature of the electrode mechanism provides a new access to the Gibbs energies of cation transfer. The new approach was applied to estimate the Gibbs energies of transfer of the cationic forms of the amino acids phenylalanine (Phe) and alanine (Ala). Fig. 6 shows the voltammetric response of iodine reduction recorded in the aqueous phase containing $0.3 \mathrm{~mol} \mathrm{dm}^{-3} \mathrm{HCl}$ and $0.25 \mathrm{~mol} \mathrm{dm}^{-3}$ Phe (curve 1) or Ala (curve 2). The peak current ratio is 0.745 and 0.661 for Phe and Ala, respectively. Utilising the calibration line given in Fig. 4, which corresponds to the equation $I_{\mathrm{p}}(\mathrm{II}) / I_{\mathrm{p}}(\mathrm{I})=$ $-0.0105 \Delta_{\mathrm{W}}^{\mathrm{NB}} G_{\mathrm{Cat}^{+}}^{\theta} / \mathrm{kJ} \mathrm{mol}^{-1}+0.9445$, the following values of the standard Gibbs energies of transfer were estimated: $\Delta_{\mathrm{W}}^{\mathrm{NB}} G_{\text {Phe }}^{\theta}=19 \mathrm{~kJ} \mathrm{~mol}^{-1}$ and $\Delta_{\mathrm{W}}^{\mathrm{NB}} G_{\text {Ala }}^{\theta}=27$ $\mathrm{kJ} \mathrm{mol}^{-1}$. These values are in close agreement with literature data 20 and $29.5 \mathrm{~kJ} \mathrm{~mol}^{-1}$ [16]. Further, the following data were determined for the cations of other

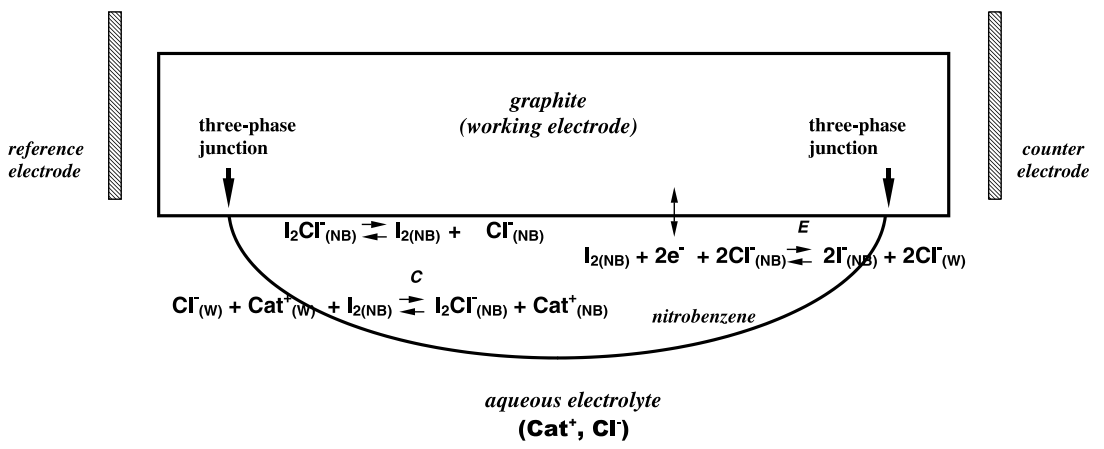

Fig. 5. Electrode assembly with a droplet of NB containing dissolved iodine attached to the graphite electrode, which is immersed in an AQ electrolyte solution containing chloride ions. 


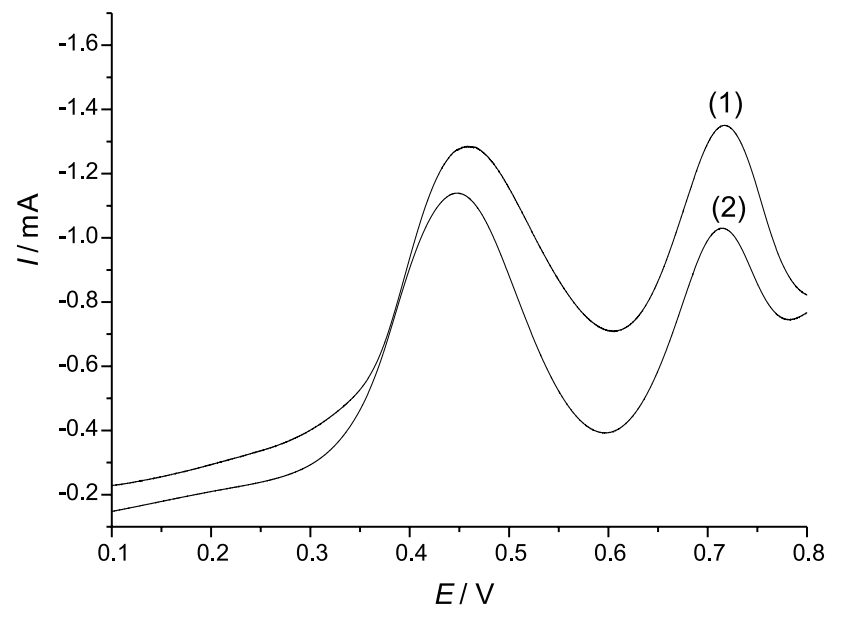

Fig. 6. SW voltammetric response of NB droplet containing $0.1 \mathrm{~mol}$ $\mathrm{dm}^{-3}$ iodine attached to a paraffin impregnated graphite electrode, which was immersed in the AQ phase containing $0.3 \mathrm{~mol} \mathrm{dm}^{-3} \mathrm{HCl}$ and $0.25 \mathrm{~mol} \mathrm{dm}^{-3}$ phenylalanine (curve 1) and alanine (curve 2). Other experimental conditions were the same as in Fig. 1.

amino acids: valine $25.60 \mathrm{~kJ} \mathrm{~mol}^{-1}$, leucine $28.90 \mathrm{~kJ}$ $\mathrm{mol}^{-1}$, tyrosine $20.04 \mathrm{~kJ} \mathrm{~mol}^{-1}$, lysine $28.71 \mathrm{~kJ} \mathrm{~mol}^{-1}$, histidine $29.09 \mathrm{~kJ} \mathrm{~mol}^{-1}$.

\section{Conclusion}

This study shows that the reduction of iodine in the three-phase arrangement graphite|NB droplet with dissolved iodine|aqueous chloride solution, a reactive partition of chloride occurs that is controlled by the Gibbs energy of transfer of the co-partitioned cations. The voltammetric response depends on the Gibbs energy of cation transfer and allows the determination of these data. In the case of the calibration systems that stretches from 5 to $35 \mathrm{~kJ} \mathrm{~mol}^{-1}$, the dependence of the peak current ratios $I_{\mathrm{p}}(\mathrm{II}) / I_{\mathrm{p}}(\mathrm{I})$ on $\Delta_{\mathrm{W}}^{\mathrm{NB}} G_{\mathrm{Cat}^{+}}^{\theta}$ was linear. It is a disadvantage of the iodine/iodide system that compounds that undergo chemical reactions with iodine or iodide cannot be studied, as well as compounds that posses an electrochemical activity in the used potential range. Since the proposed determination of the Gibbs energies of ion transfer is based on measuring a peak current, i.e. a kinetic value, applications must be done with scrupulous care to avoid erroneous results.

\section{Acknowledgements}

V. Mirčeski thanks A. v. Humboldt-Stiftung for provision of a research fellowship, R. Gulaboski thanks Deutscher Akademischer Austauschdienst (DAAD) for provision of a Ph.D. scholarship, and F. Scholz acknowledges support by Deutsche Forschungemeinschaft (DFG) and Fonds der Chemischen Industrie (FCI).

\section{References}

[1] M. Lovrić, F. Scholz, J. Solid State Electrochem. 1 (1997) 108.

[2] F. Scholz, B. Meyer, in: A.J. Bard, I. Rubinstein (Eds.), Electroanalytical Chemistry, A Series of Advances, vol. 20, Marcel Dekker, New York, 1998, p. 1.

[3] F. Marken, R.D. Webster, S.D. Bull, S.G. Davies, J. Electroanal. Chem. 437 (1997) 209.

[4] F. Marken, A.N. Blythe, J.D. Wadhawan, R.G. Compton, S.D. Bull, R.T. Aplin, S.G. Davies, J. Solid State Electrochem. 5 (2001) $17-22$.

[5] J.D. Wadhawan, R.G. Compton, F. Marken, S.D. Bull, S.G. Davies, J. Solid State Electrochem. 5 (2001) 348-354.

[6] U. Schröder, R.G. Compton, F. Marken, S.D. Bull, S.G. Davies, S. Gilmour, J. Phys. Chem. B 105 (2001) 1344.

[7] F. Scholz, S. Komorsky-Lovrić, M. Lovrić, Electrochem. Commun. 2 (2000) 112.

[8] Š. Komorsky-Lovrić, M. Lovrić, F. Scholz, J. Electroanal. Chem. 508 (2001) 129.

[9] Š. Komorsky-Lovrić, M. Lovrić, F. Scholz, Collect. Czech. Chem. Commun. 66 (2001) 434.

[10] V. Mirčeski, F. Scholz, J. Electroanal. Chem. 522 (2002) 189.

[11] Alexander G. Volkov (Ed.), Liquid Interfaces in Chemical, Biological, and Pharmaceutical Applications, Marcel Dekker, New York, 2001, p. 683.

[12] E.V. Dehmlow, S.S. Dehmlow, Phase Transfer Catalysis, Verlag Chemie, Weinheim, 1980.

[13] H. Katano, M. Senda, Anal. Sci. 17 (1998) 63.

[14] C.J. Bender, Chem. Soc. Rev. 17 (1988) 317.

[15] C. Shi, F.C. Anson, J. Phys. Chem. B 105 (2001) 1047.

[16] Y. Takeda, T. Ezaki, Y. Kudo, H. Matsda, Bull. Chem. Jpn. 68 (1995) 787.

[17] Y. Marcus, in: Ion Properties, Marcel Dekker, New York, 1997, p. 216.

[18] J.E. Huheey, in: Anorganische Chemie Prinzipien von Struktur und Reaktivität, Walter de Gruyter, Berlin, New York, 1988, p. 853.

[19] J.J. O‘Dea, J. Osteryoug, R.A. Osteryoung, Anal.Chem. 53 (1981) 695.

[20] B. Liu, M.V. Mirkin, in: A.G. Volkov (Ed.), Liquid Interfaces in Chemical Biological and Pharmaceutical Applications, Marcel Dekker, New York, 2001, p. 385. 